\title{
Front Matter: Volume 7544
}

, "Front Matter: Volume 7544," Proc. SPIE 7544, Sixth International Symposium on Precision Engineering Measurements and Instrumentation, 754401 (23 February 2011); doi: 10.1117/12.888137

SPIE Event: Sixth International Symposium on Precision Engineering SPIE. Measurements and Instrumentation, 2010, Hangzhou, China 


\section{PROCEEDINGS OF SPIE}

\section{Sixth International Symposium on Precision Engineering Measurements and Instrumentation}

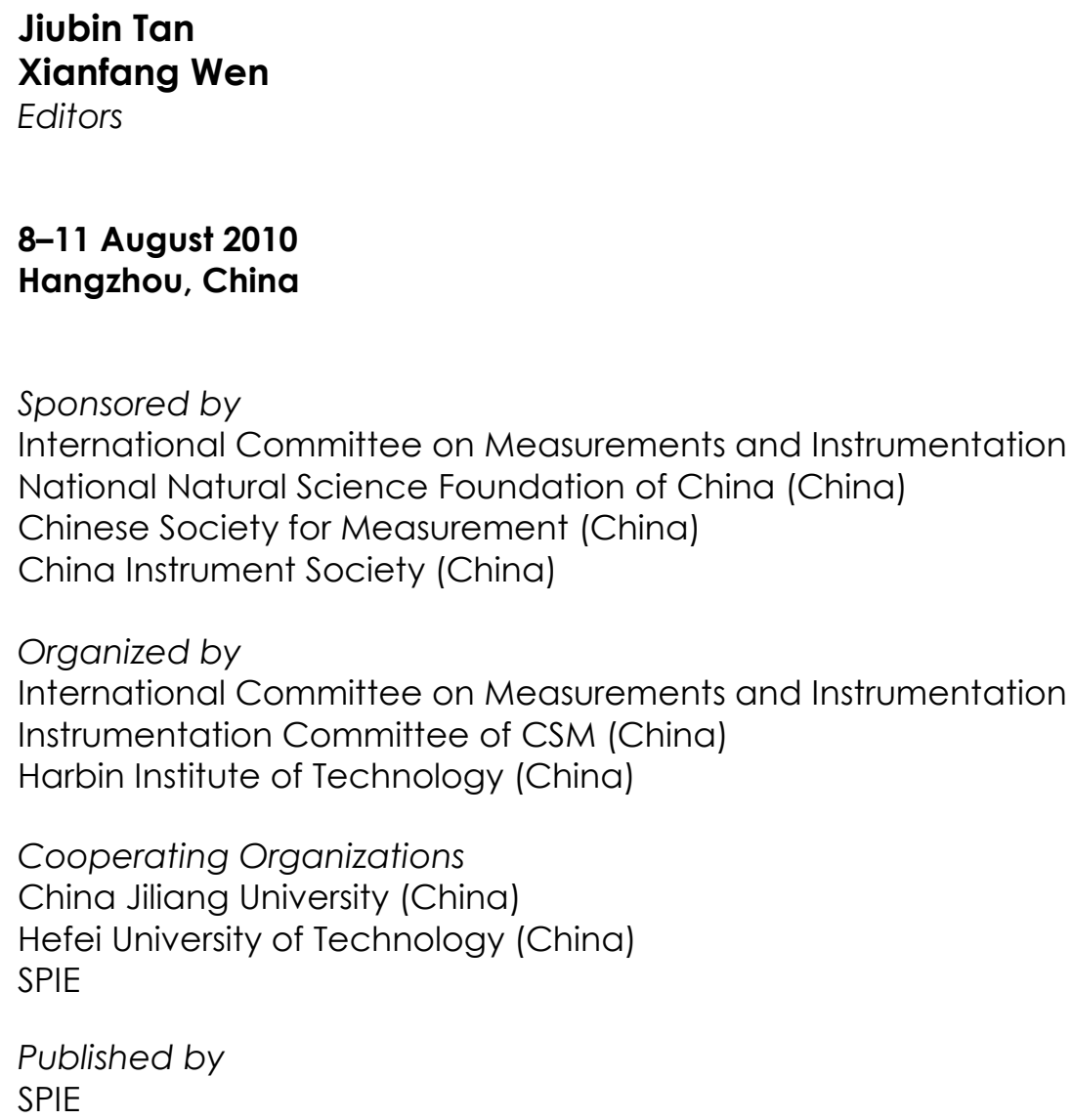


The papers included in this volume were part of the technical conference cited on the cover and title page. Papers were selected and subject to review by the editors and conference program committee. Some conference presentations may not be available for publication. The papers published in these proceedings reflect the work and thoughts of the authors and are published herein as submitted. The publisher is not responsible for the validity of the information or for any outcomes resulting from reliance thereon.

Please use the following format to cite material from this book:

Author(s), "Title of Paper," in Sixth International Symposium on Precision Engineering Measurements and Instrumentation, edited by Jiubin Tan, Xianfang Wen, Proceedings of SPIE Vol. 7544 (SPIE, Bellingham, WA, 2010) Article CID Number.

ISSN 0277-786X

ISBN 9780819479402

Published by

SPIE

P.O. Box 10, Bellingham, Washington 98227-0010 USA

Telephone +1 3606763290 (Pacific Time) · Fax +1 3606471445

SPIE.org

Copyright (C) 2010, Society of Photo-Optical Instrumentation Engineers

Copying of material in this book for internal or personal use, or for the internal or personal use of specific clients, beyond the fair use provisions granted by the U.S. Copyright Law is authorized by SPIE subject to payment of copying fees. The Transactional Reporting Service base fee for this volume is $\$ 18.00$ per article (or portion thereof), which should be paid directly to the Copyright Clearance Center (CCC), 222 Rosewood Drive, Danvers, MA 01923. Payment may also be made electronically through CCC Online at copyright.com. Other copying for republication, resale, advertising or promotion, or any form of systematic or multiple reproduction of any material in this book is prohibited except with permission in writing from the publisher. The CCC fee code is 0277-786X/10/\$18.00.

Printed in the United States of America.

Publication of record for individual papers is online in the SPIE Digital Library.

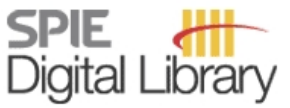

SPIEDigitalLibrary.org

Paper Numbering: Proceedings of SPIE follow an e-First publication model, with papers published first online and then in print and on CD-ROM. Papers are published as they are submitted and meet publication criteria. A unique, consistent, permanent citation identifier (CID) number is assigned to each article at the time of the first publication. Utilization of CIDs allows articles to be fully citable as soon they are published online, and connects the same identifier to all online, print, and electronic versions of the publication. SPIE uses a six-digit CID article numbering system in which:

- The first four digits correspond to the SPIE volume number.

- The last two digits indicate publication order within the volume using a Base 36 numbering system employing both numerals and letters. These two-number sets start with 00, 01, 02, 03, 04, $05,06,07,08,09,0 A, 0 B \ldots 0 Z$, followed by 10-1Z, 20-2Z, etc.

The CID number appears on each page of the manuscript. The complete citation is used on the first page, and an abbreviated version on subsequent pages. Numbers in the index correspond to the last two digits of the six-digit CID number. 


\title{
Contents
}

\section{Part One}

\author{
xxv Conference Committees \\ xxxi Introduction from Li Zhu \\ xxxiii Introduction from Jiubin Tan
}

\section{INSTRUMENTATION THEORY AND METHODOLOGY}

754402 Factorial tests for the air beam assisted form error in-process optical measurement [7544-306]

Y. Zhang, Y. Gao, K. Li, Hong Kong Univ. of Science and Technology (Hong Kong, China)

754403 Analysis of angle measurement uncertainty for wMPS [7544-115]

L. Geng, Tianjin Univ. (China) and Tianjin Polytechnic Univ. (China); J. Zhu, X. Yang, Z. Xiong, Tianjin Univ. (China)

754404 In-situ optical measurement of separation angles between bifacial lines in large scale space [7544-111]

H. W. Zhang, G. X. Zhang, Z. R. Qiu, W. C. Hu, M. Liu, Tianjin Univ. (China)

$754405 \quad$ Higher order harmonics contribution and suppression in metrology beamline [7544-48]

H. Zhou, G. Wang, J. Zheng, T. Hou, K. Qiu, Univ. of Science and Technology of China (China)

754406 Dual autofocusing algorithm for optical lens measurement system [7544-357]

Z. Zhang, H. Hu, Harbin Institute of Technology Shenzhen Graduate School (China)

$754407 \quad$ Evaluation of vehicle ride comfort based on neural network [7544-276]

Y. Gao, R. Tang, J. Liang, Jilin Univ. (China); S. Shen, Beijing Aviation Precision Machinery Research Institute (China); J. Liang, H. Sun, Jilin Univ. (China)

754408 Analysis of the performance of multi-channel measurement system [7544-119] Y. Li, Y. Liu, National Time Service Ctr. (China), Graduate Univ. of the Chinese Academy of Sciences (China), and Key Lab. of Time and Frequency Primary Standards (China); X. Li, National Time Service Ctr. (China) and Key Lab. of Time and Frequency Primary Standards (China)

754409 Transmission delay measurement for converter [7544-168]

H. Zhang, National Time Service Ctr. (China), Key Lab. of Precision Navigation and Timing Technology (China), and Graduate Univ. of the Chinese Academy of Sciences (China); X. Li, National Time Service Ctr. (China) and Key Lab. of Precision Navigation and Timing Technology (China); L. Xu, National Time Service Ctr. (China), Key Lab. of Precision Navigation and Timing Technology (China), and Graduate Univ. of the Chinese Academy of Sciences (China); Y. Xue, National Time Service Ctr. (China) and Key Lab. of Precision Navigation and Timing Technology (China) 
7544 OA Detection of abnormal data during dynamic measurement of discontinuous surfaces [7544-274]

H. Meng, L. Zhu, Q. Chen, Beijing Information Science and Technology Univ. (China)

$7544 \mathrm{OB} \quad$ Estimation of the uncertainty propagation in verification operator of cylindricity errors [7544-83]

F. Zhao, L. Zhang, P. Zheng, Zhengzhou Univ. (China)

7544 OC Color recognition system for urine analyzer [7544-278]

L. Zhu, Harbin Institute of Technology (China) and Beijing Information Science and Technology Univ. (China); Z. Wang, Harbin Institute of Technology (China); Q. Lin, M. Dong, Beijing Information Science and Technology Univ. (China)

7544 OD Dual magnetic circuit magnetic bead coagulation test method [7544-277] L. Zhu, Harbin Institute of Technology (China) and Beijing Information Science and Technology Univ. (China); Z. Wang, Harbin Institute of Technology (China); S. Guo, J. Wang, Beijing Information Science and Technology Univ. (China)

$7544 \mathrm{OE} \quad$ The challenge in the application of new generation geometrical product specifications [7544-292]

Z. Zhao, X. Li, H. Zhao, B. Li, Zhongyuan Univ. of Technology (China)

7544 OF Mechanism of STED microscopy and analysis of the factors affecting resolution [7544-252] Y. Peng, Changchun Institute of Optics, Fine Mechanics and Physics (China) and Graduate Univ. of the Chinese Academy of Sciences (China); A. Hua, Changchun Institute of Optics, Fine Mechanics and Physics (China)

\section{MEASUREMENT FOR PRECISION AND ULTRA-PRECISION MACHINING}

7544 OG Thermal conductivity and thermal linear expansion measurements on molten salts for assessing their behaviour as heat transport fluid in thermodynamics solar systems (Invited Paper) [7544-343]

P. Coppa, G. Bovesecchi, Univ. of Rome Tor Vergata (Italy); F. Fabrizi, SolTerm (Italy)

$7544 \mathrm{OH} \quad$ Final manufacturing and measurement of satellite proof masses for the MICROSCOPE project (Invited Paper) [7544-01]

O. Jusko, N. Gerwien, D. Hagedorn, F. Härtig, H.-P. Heyne, U. Langner, F. Löffler, S. Metschke, M. Neugebaver, H. Reimann, Physikalisch-Technische Bundesanstalt (Germany)

7544 Ol LDGI signal subdivision by soft computing for nanomeasurement (Invited Paper) [7544-135] K.-C. Fan, Hefei Univ. of Technology (China) and National Taiwan Univ. (Taiwan); F. Cheng, Hefei Univ. of Technology (China)

$75440 \mathrm{~J} \quad$ Edge profile measurement of micro-cutting tools on a diamond turning machine [7544-233] T. Asai, S. H. Jang, Y. Arai, W. Gao, Tohoku Univ. (Japan)

7544 OK Development of pneumatic actuator with low-wave reflection characteristics [7544-285] H. Chang, T. T. Tsung, C. S. Jwo, J. C. Chiang, National Taipei Univ. of Technology (Taiwan) 
$7544 \mathrm{OL} \quad$ Feasibility and challenge for measurement of transparent object by adopting differential interference contrast technology [7544-125]

S.-K. Yu, National Tsing Hua Univ. (Taiwan); T.-K. Liu, Industrial Technology Research Institute (Taiwan); C.-C. Liu, W.-L. Chen, S.-C. Lin, National Tsing Hua Univ. (Taiwan)

7544 OM Effects of water flow rate on transparent window size for form error in-process optical measurement [7544-310]

Y. Gao, J. X. Wang, Y. Zhang, Y. Lai, Hong Kong Univ. of Science and Technology (Hong Kong, China)

7544 ON Reflective-type optical encoder based on fractional Talbot self-image effect using phase grating [7544-348]

C.-F. Kao, MingDao Univ. (Taiwan); S.-H. Lu, Feng Chia Univ. (Taiwan)

$754400 \quad$ Three-dimensional angular measurement based on moiré fringe [7544-282]

W. Wang, J. Tan, L. Deng, H. Liu, National Univ. of Defense Technology (China); J. Yang, National Univ. of Defense Technology (China) and National Lab. of Space Intelligent Control (China)

7544 OP Slide error measurement of a large-scale ultra-precision lathe [7544-234]

J. C. Lee, W. Gao, Y. J. Noh, Tohoku Univ. (Japan); J. H. Hwang, J. S. Oh, C. H. Park, Korea Institute of Machinery and Materials (Korea, Republic of)

7544 OQ Development of GJ-4G track inspection car [7544-307]

S. Ren, Beijing Jiaotong Univ. (China) and Ministry of China Railway (China); S. Gu, G. Xu, Ministry of China Railway (China); Z. Gao, Q. Feng, Beijing Jiaotong Univ. (China)

7544 OR Dynamic error correction method for time grating CNC rotary table [7544-200]

X. Liu, J. Feng, F. Zheng, D. Peng, Chongqing Univ. of Technology (China)

7544 OS Measurement of damping properties of damping material [7544-296]

C. Cai, Q. Sun, National Institute of Metrology (China)

7544 OT Landmark measurement of Hanjiangfish fossil based on digital modeling [7544-242] Y. Wang, J. Ouyang, P. Qin, Tianjin Univ. (China)

$7544 \mathrm{OU} \quad$ On-line monitoring system for skiving of NdFeB laminate components [7544-188]

Y. Li, Q. Chen, Y. LU, Beijing Information Science \& Technology Univ. (China)

7544 OV Three-dimensional profile measurement based on light-section method [7544-319] S. Wang, Q. Zhao, Z. Wang, X. Zhou, Southwest Jiaotong Univ. (China)

7544 OW Evaluation of roundness error based on improved area hunting method [7544-178] W. Zhan, Z. Xue, National Institute of Metrology (China); Y. Wu, China Jiliang Univ. (China)

7544 OX Motion error analysis of profilometer with grating-inductance combination [7544-124] X. Wang, HuBei Univ. of Technology (China) and HuBei Key Lab. of Manufacture Quality Engineering (China); Y. Wu, HuBei Univ. of Technology (China); L. Yang, HuBei Univ. of Technology (China) and HuBei Key Lab. of Manufacture Quality Engineering (China); L. Wei, HuBei Univ. of Technology (China) 
7544 OY Design of aerostatic bearing restrictor with multi-loop coupling pocket [7544-174] J. YU, B. Fang, T. Guo, D. Li, W. Zhang, China Jiliang Univ. (China)

$75440 Z$ Comparison of three TCC calculation algorithms for partially coherent imaging simulation [7544-23]

X. Wu, S. Liu, W. Liu, T. Zhou, L. Wang, Huazhong Univ. of Science and Technology (China)

$754410 \quad$ Influence of ecological factors on pepper blade thickness [7544-322]

L. Guo, T. Guo, B. Fang, D. Li, China Jiliang Univ. (China)

$754411 \quad$ Precise stage design with planar diffraction grating interferometer [7544-17]

H. Xia, Y. Fei, Hefei Univ. of Technology (China)

754412 Coordinate measurement method based on coding target [7544-237]

M. Zhao, Z. Qiu, H. Liu, Xi'an Univ. of Technology (China)

754413 Calibration method for large internal micrometer with three-point contact [7544-50]

R. T. Sui, Beijing Orient Institute for Measurement \& Test (China)

754414 Design of internal screw thread measuring device based on the Three-Line method principle [7544-226]

D. Hu, J. Chen, Shanghai Institute of Technology (China)

754415 Image segmentation algorithm for location of laser spots during aircraft relative attitude determination [7544-272]

B. Hou, X. Ding, Harbin Institute of Technology (China)

754416 Measurement of water jet diameter for determination of line width of water jet-guided laser [7544-93]

Z. Zhi, Y. Zhang, M. Shan, Harbin Engineering Univ. (China); Y. Wang, Tieling Teachers College (China)

\section{NOVEL INSTRUMENT AND MEASUREMENT SYSTEM}

754417 A novel micro-friction measuring-head using force-feedback compensation (Invited Paper) [7544-316]

D. G. Chetwynd, M. S. Alsoufi, Univ. of Warwick (United Kingdom)

754418 Aspects of probing on the micro scale (Invited Paper) [7544-03]

E. J. C. Bos, Xpress Precision Engineering B.V. (Netherlands)

754419 Dual wavelength fluorescent ratiometric pH measurement by scanning near-field optical microscopy [7544-06]

Y. Li, R. Shinohara, K. Iwami, Y. Ohta, N. Umeda, Tokyo Univ. of Agriculture and Technology (Japan)

7544 1A Development of ultra-precision micro-cavity measurement technique in HIT-UOI [7544-262] J. Cui, L. Li, J. Tan, Harbin Institute of Technology (China) 
7544 1B Compensation of laser beam directional stability offset error by using translational spectroscope [7544-260]

J. Li, X. Ding, J. Cui, J. Tan, Harbin Institute of Technology (China)

7544 1C Development of high-precision high-frequency phase-shifting circuit [7544-176]

S. Ye, J. Song, B. Zhang, J. Qiu, China Jiliang Univ. (China)

7544 1D Development of a near-infrared spectroscopic system for monitoring urine glucose level for the use of long-term home healthcare [7544-332]

S. Tanaka, Y. Hayakawa, M. Ogawa, K. Yamakoshi, Kanazawa Univ. (Japan)

7544 IE High precision multimatrix optic-electronic modules for distributed measuring systems [7544-352]

V. V. Korotaev, I. A. Konyakhin, A. N. Timofeev, S. N. Yaryshev, Saint-Petersburg State Univ. of Information Technologies, Mechanics and Optics (Russian Federation)

7544 IF Design of durability testing system for motorcycle engine ECU [7544-136]

J. Guo, M. Yu, S. Liu, G. Yan, Chongqing Univ. (China)

$75441 G \quad$ Instrument for measuring moment of inertia with high precision [7544-187]

Y. Zheng, M. Lin, B. Guo, China Jiliang Univ. (China)

$7544 \mathrm{1H} \quad$ Nonlinear control of maglev positioning stage [7544-66]

W.-M. Wang, S.-Y. Ma, W.-Q. Wang, D.-C. Li, Beijing Institute of Technology (China)

$754411 \quad$ Design and analysis of two dimensional X-Y micropositioning stage [7544-54]

W. Wang, Z. Zhu, Z. Chen, Zhejiang Univ. (China)

$75441 \mathrm{~J} \quad$ Precision positioning system based on intelligent Fuzzy-PID control [7544-334]

Z. Liu, L. Zhang, Y. Li, Tsinghua Univ. (China)

7544 1K Development of DSP and FPGA based 4-axis motion controller [7544-38]

S. He, X. Gao, C. Peng, Y. Zhang, Southwest Jiaotong Univ. (China)

$75441 \mathrm{~L} \quad$ A 2D coplanar translation stage with synchronous XY position metrology for surface scanning measurement [7544-236]

K. Xian, L. Zhou, X. Liu, Huazhong Univ. of Science and Technology (China)

$75441 \mathrm{M}$ Multi-component gas analyzer based on Fourier transform spectrometer [7544-76]

L.-B. Ren, H.-Y. Wei, Y. Li, Tsinghua Univ. (China)

$75441 \mathrm{~N}$ Operational amplifier-based micro eddy current sensor and its application in abrasive machining (honing) [7544-141]

F. Gu, X. Ye, H. Gao, H. Wang, National Institute of Metrology (China); J. Xie, National Institute of Metrology (China) and China Jiliang Univ. (China)

$754410 \quad$ Micro mixer based on surface acoustic wave driving [7544-167]

G. Zhang, Y. Li, J. Zhang, C. Yang, J. Liu, Shanghai Jiao Tong Univ. (China) 
7544 IP 3D mosaic method in monocular vision measurement system for large-scale equipment [7544-77]

Q. Xu, Henan Univ. of Science and Technology (China); J. Wang, Harbin Wavetek Co., Ltd. (China); R. Che, Harbin Institute of Technology (China)

$75441 Q \quad$ Modulation transfer function measurement technique for image sensor arrays [7544-341] H. Jin, H. Jiang, X. Zhang, Changchun Univ. of Science and Technology (China) and Changchun Institute of Optics, Fine Mechanics and Physics (China)

7544 IR ECT image reconstruction based on the generalized vector sampled pattern matching method [7544-39]

Y. Liu, Y. Zhao, Y. Peng, Yanshan Univ. (China)

7544 is The retardation measurement of multiple-order wave plates using white-light Michelson interferometer [7544-05]

J. Wang, L. Chen, B. Li, L. Shi, T. Luo, Nanjing Univ. of Science and Technology (China)

$75441 \mathrm{~T} \quad$ Valve torque measuring device based on strain gauge [7544-26]

Q. Zhu, F. Ni, G. Yang, B. Li, Tongji Univ. (China)

$75441 \mathrm{U}$ Wavelength readout system constructed of fiber Fabry-Perot tunable filter and virtual instrument [7544-79]

C. Lü, R. Zhang, P. Cheng, K. Li, X. Wu, C. Ge, Tianjin Univ. (China)

$75441 \mathrm{~V} \quad$ Noise suppression during the electro-magnetic acoustic detection of wheels tread defects [7544-12]

X. Zhou, L. Dai, K. Yang, L. Wang, Southwest Jiaotong Univ. (China)

7544 1W Development of a surface topography instrument for automotive textured steel plate [7544-231]

Z. Wang, Hubei Automotive Industries Institute (China); S. Wang, Hubei Automotive Industries Institute (China) and Huazhong Univ. of Science and Technology (China); Y. Chen, Hubei Automotive Industries Institute (China); T. Xie, Huazhong Univ. of Science and Technology (China)

$75441 \mathrm{X} \quad$ Additional spread spectrum modulation timing method in BPC [7544-298]

P. Feng, G. Wu, Y. Bai, X. Ding, National Time Service Ctr. (China)

7544 1Y Analysis of electrical tomography sensitive field based on multi-terminal network and electric field [7544-222]

Y. He, X. Su, M. Xu, Civil Aviation Univ. of China (China); H. Wang, Tianjin Univ. (China)

754412 Shape apperception and reconstruction of fiber grating intelligent flexible structure based on orthogonal curvatures [7544-32]

X. Zhu, B. Sun, L. Shen, L. Jiang, J. Yi, Shanghai Univ. (China)

754420 Portable minimally invasive human glucose detection instrument by surface plasmon resonance [7544-353]

D. Li, P. Wu, J. Zhang, W. Liang, K. Xu, Tianjin Univ. (China) 
754421 Design of co-path scanning long trace profiler for measurement of $x$-ray space optical elements [7544-137]

L. Shun, Changchun Institute of Optics, Fine Mechanics and Physics (China) and Graduate School of the Chinese Academy of Sciences (China); G. Yan, Z. Wei, Changchun Institute of Optics, Fine Mechanics and Physics (China); Z. Yang, Changchun Institute of Optics, Fine Mechanics and Physics (China) and Graduate School of the Chinese Academy of Sciences (China)

754422 Intelligent seismic sensor with double three component MEMS accelerometers [7544-80] J. Fu, J. Wang, Z. Li, X. Liu, Institute of Crustal Dynamics (China); Z. Wang, Beihang Univ. (China)

754423 3D measurement system based on computer-generated gratings [7544-43]

Y. Zhu, W. Pan, Y. Luo, Zhejiang Univ. of Science and Technology (China)

754424 Offset frequency generator with low noise [7544-304]

W. Wang, Y. Liu, H. Zhang, X. Li, National Time Service Ctr. (China) and Key Lab. of Time and Frequency Primary Standard (China)

754425 Residual voltage of the electrical equipment [7544-56]

J. Yuan, X. Qian, J. Qian, China Jiliang Univ. (China)

754426 Non-contact measurement of cylindricity error using digital fringe projection profilometry [7544-19]

P. Zheng, L. Zhang, F. Zhao, Zhengzhou Univ. (China)

754427 Solving SOC test scheduling problem using cross-entropy method [7544-279]

L. Deng, L. Qiao, X. Peng, Harbin Institute of Technology (China)

754428 Optimization and analysis of variable fiber optic attenuator with DMD using ZEMAX [7544-149]

Z. Zhong, L. Cheng, M. Shan, Harbin Engineering Univ. (China); S. Lang, Harbin Normal Univ. (China)

754429 Measurement of attitude angles of single stator multi-degrees of freedom ultrasonic motor [7544-180]

W. Liu, Z. Tao, L. Zhang, J. Gao, F. Zhao, P. Zhen, Zhengzhou Univ. (China)

7544 2A Measurement of curvature radius using phase retrieval with volume speckle field [7544-146] M. Shan, P. Zhi, Z. Zhong, Harbin Engineering Univ. (China); B. Zhu, Harbin Institute of Technology (China)

7544 2B Measurement of whole tire profile [7544-254]

Y. Yang, W. Jiao, Hefei Univ. of Technology (China)

$75442 \mathrm{C}$ Scanning white-light interferometric measurement of free form surface based on interference fringe tracing [7544-223]

S. Chang, Huazhong Univ. of Science and Technology (China); S. Wang, Louyang Institute of Science and Technology (China); T. Xie, W. Pan, Huazhong Univ. of Science and Technology (China) 
7544 2D Accuracy design of double parallel-joints coordinate measuring machine [7544-293] G. Xia, Hefei Univ. of Technology (China) and Jiujiang Precision Measuring Technology Research Institute (China); Y. Fei, Hefei Univ. of Technology (China); J. Zhao, Jiujiang Precision Measuring Technology Research Institute (China)

\section{Part Two}

\section{MODERN OPTICS AND INSTRUMENTS FOR PRECISION MEASUREMENT}

$75442 \mathrm{E} \quad$ In-situ lateral confocal microscopic surface profilometry with vibration-resistance capability (Invited Paper) [7544-195]

L.-C. Chen, C.-K. Li, Y.-W. Chang, National Taipei Univ. of Technology (Taiwan)

7544 2F Confocal axial beam scanning through LC-SLM [7544-170]

L. Zou, J. Dong, Z. Fan, Harbin Institute of Technology (China)

$75442 \mathrm{G} \quad$ Error correction technology of the length grating measuring system [7544-300]

X. Shu, Y. Zuo, X. Xu, Changcheng Institute of Metrology and Measurement (China)

$75442 \mathrm{H} \quad$ Polarization phase-shifting interference microscopy for ultra-precision surface topography [7544-321]

W. Cheng, X. Chen, L. Zhou, X. Liu, Huazhong Univ. of Science and Technology (China)

75442 Application of digital holographic interferometry based on EALCD for measurement of displacement [7544-100]

J. Guo, W. Zhang, H. Dong, Y. Zhou, W. Wang, Changchun Univ. of Science and Technology (China)

$75442 \mathrm{~J} \quad$ Measurement of refractive index of active photopolymer films [7544-186]

A. Gao, Q. Hu, Q. Zhai, L. Qiu, S. Tao, Beijing Univ. of Technology (China)

$75442 \mathrm{~K}$ Whole-field measurement of strain based on digital speckle correlation method [7544-216] Y. Wang, C. Fang, Hefei Univ. of Technology (China); L. Yang, Hefei Univ. of Technology (China) and Oakland Univ. (United States)

$75442 \mathrm{~L} \quad$ Application of machine vision based measurement in precise assembly of miniature parts [7544-270]

C. Zhu, X. Wang, X. Zhang, L. Wang, Y. Luo, Dalian Univ. of Technolgy (China)

$75442 \mathrm{M} \quad$ Laser beam levelness measuring and adjusting instrument based on video graduation technology [7544-47]

Y. Shan, J. Zhao, M. Zhou, M. Yang, China Jiliang Univ. (China)

$75442 \mathrm{~N} \quad$ White-light spectral scanning interferometry for surface measurement system [7544-154] C. Wang, Zhejiang Univ. (China); N. Cao, Changchun Institute of Optics, Fine Mechanics and Physics (China); J. Lu, J. Guan, Zhejiang Univ. (China) 
754420 Dew condensation sensor based on surface plasmon resonance of periodic silver nanostructure on AT-cut quartz crystal (Invited Paper) [7544-04]

H. Nagasaki, K. Iwami, Tokyo Univ. of Agriculture and Technology (Japan); T. Tanahashi, Espec Corp. (Japan); N. Umeda, Tokyo Univ. of Agriculture and Technology (Japan)

7544 2P High-temperature microelectromechanical pressure sensors based on a SOI heterostructure for an electronic automatic aircraft engine control system (Invited Paper) [7544-255]

L. V. Sokolov, FSUE Institute of Aircraft Equipment (Russian Federation)

$75442 Q \quad$ Measurement of pseudo-range with digital television broadcasting signal [7544-152] K. Song, National Time Service Ctr. (China), Key Lab. of Precision Navigation and Timing Technology (China), and Graduate Univ. of the Chinese Academy of Sciences (China); W. Guo, National Time Service Ctr. (China) and Key Lab. of Precision Navigation and Timing Technology (China); C. Huang, National Time Service Ctr. (China), Key Lab. of Precision Navigation and Timing Technology (China), and Graduate Univ. of the Chinese Academy of Sciences (China); S. Li, National Time Service Ctr. (China) and Key Lab. of Precision Navigation and Timing Technology (China); H. Zhang, National Time Service Ctr. (China), Key Lab. of Precision Navigation and Timing Technology (China), and Graduate Univ. of the Chinese Academy of Sciences (China)

$75442 \mathrm{R} \quad$ Contactless power feeding for ocean buoy [7544-339]

X.-F. Li, C. Li, J. Lin, Tianjin Univ. (China); Q. Zhang, Tianjin Univ. (China) and Tianjin Univ. of Science and Technology (China)

754425 Theoretical model and optimization of magnetic stress sensor for measuring steel cable stress [7544-311]

L. Liu, W. Chen, P. Zhang, S. Hu, Chongqing Univ. (China)

$75442 \mathrm{~T}$ High accuracy star image locating and imaging calibration for star sensor technology [7544-103]

S. Zhang, Z. Zhang, Changchun Institute of Optics, Fine Mechanics and Physics (China) and Graduate Univ. of the Chinese Academy of Sciences (China); H. Sun, Y. Wang, Changchun Institute of Optics, Fine Mechanics and Physics (China)

$75442 \mathrm{U}$ Capacitive lamb wave transducers with multiple even-modes for biochemical detections [7544-197]

L.-F. Ge, J.-P. Shao, Anhui Univ. (China)

$75442 \mathrm{~V} \quad$ Fiber Bragg grating displacement sensor research based on edge filter demodulation [7544-191]

Y. Huang, Nanjing Univ. of Posts and Telecommunications (China)

$75442 \mathrm{~W}$ Study of adsorption technology and design of magnetic adsorption device about wallclimbing robot [7544-128]

F. Yuan, L. Wang, Henan Univ. of Technology (China) 
7544 2X Piezoelectric energy harvesting from ultrasonic vibration in fluid environments [7544-295] G. Tang, Shanghai Jiaotong Univ. (China) and Nanchang Institute of Technology (China); C. Zheng, J. Liu, Y. Li, Shanghai Jiaotong Univ. (China); H. Liu, Shanghai Jiaotong Univ. (China) and Nanchang Univ. (China); C. Yang, Shanghai Jiaotong Univ. (China); D. He, National Engineering Research Ctr. for Nanotechnology (China)

$75442 Y \quad$ Task-oriented design of a fully pre-stressed double-layer six-component force/torque sensor [7544-193]

H. Wang, Y. Hou, J. Yao, Z. Wang, Y. Zhao, Yanshan Univ. (China)

$75442 Z$ Design and research of sun sensor based on technology of optical fiber [7544-98]

Y. Li, W. Zhou, D. Li, Soochow Univ. (China)

754430 Hydraulic square pressure generator for dynamic calibration of pressure sensors at low frequencies [7544-283]

H. Chang, T. T. Tsung, C. S. Jwo, S. H. Wang, National Taipei Univ. of Technology (Taiwan)

754431 Hot-wire probe used for measurement of one dimensional flow with bi-direction [7544-132]

C. Tu, China Jiliang Univ. (China)

754432 Broadband wavelength converter based on segmented quasi-phase matched grating [7544-11]

T. Liu, North China Electric Power Univ. (China); B. Li, North China Electric Power Univ. (China) and Beijing Univ. of Posts and Telecommunications (China)

754433 Comparison study on disturbance estimation techniques in precise slow motion control [7544-35]

S. Fan, National Univ. of Defense Technology (China); R. Nagamune, Y. Altintas, Univ. of British Columbia (Canada); D. Fan, Z. Zhang, National Univ. of Defense Technology (China)

$754434 \quad$ Phase error estimation with broadband white light by phase diversity [7544-143]

Y. Wu, B. Wang, Z. Wang, J. Cao, Changchun Institute of Optics, Fine Mechanics and Physics (China); X. Zhang, Yanshan Univ. (China)

754435 Distorted target recognition in cluttered scene based on maximum average correlation height algorithm [7544-85]

Z. Xue, J. Shang, W. Wang, Changchun Univ. of Science and Technology (China)

754436 Image restoration for a rectangular poor-pixels detector [7544-62]

P. Wen, X. Wang, Tianjin Univ. (China); H. Wei, Univ. of Reading (United Kingdom)

754437 Improved HHT for four-way valve early fault diagnosis [7544-134]

Q. Jiang, T. Li, Y. Yao, J. Cai, China Jiliang Univ. (China)

754438 Moving object detection from moving camera sequences [7544-86]

X. Yu, X. Chen, Academy of Equipment Command and Technology (China); H. Xu, 91404

Army, PLA (China); Y. Guo, 95806 Army, PLA (China) 
754439 Detection algorithm for dimensional measurement and damage defect recognition of piston rings [7544-150]

T. He, Q. Wu, Z. Zeng, X. Lou, Y. Wu, Hubei Univ. of Technology (China) and Huazhong Univ. of Science and Technology (China)

7544 3A Sub-pixel location of center of target based on Zernike moment [7544-275]

B. Liang, M. Dong, J. Wang, B. Yan, Beijing Information Science and Technology Univ. (China)

7544 3B Study on parameters fitting of Archimedes helicoid surface [7544-280]

Q. Chen, Y. Guo, L. Zhu, H. Zou, Beijing Information Science and Technology Univ. (China)

7544 3C Model and method used for extraction of projectile motion information from radar echo [7544-29]

Y. Wang, J. Tan, Harbin Institute of Technology (China); R. Zhang, Academy of Equipment Command and Technology (China)

7544 3D Gravity matching algorithm based on intrinsic features threshold of gravitational field [7544-345]

B. Xia, Changshu Institute of Technology (China); H. Wang, S. Wang, J. Tao, Aeronautics Univ. of Air Force (China)

7544 3E Image-based automatic recognition of larvae [7544-123]

R. Sang, G. YU, W. Fan, T. Guo, China Jiliang Univ. (China)

7544 3F Monocular vision for intelligent wheelchair indoor navigation based on natural landmark matching [7544-34]

X. Xu, Univ. of Electronic Science and Technology of China (China); Y. Luo, W. Kong,

Chongqing Univ. of Posts and Telecommunications (China)

7544 3G Identification defect character of MMM signals based on wavelet singular entropy and RBFNN [7544-338]

L. Zhang, Y. Zhao, China Univ. of Petroleum (China); C. Tian, Offshore Oil Engineering (Qingdao) Co., Ltd. (China)

$75443 \mathrm{H} \quad$ Binary optics pyroelectric chopper technology [7544-243]

$\mathrm{X}$. Hu, J. Yuan, L. Long, Kunming Institute of Physics (China)

$754431 \quad$ A multi-sensor image registration algorithm of window segmentation based on SIFT point and line features vector [7544-169]

Y. Jiang, Wuhan Univ. (China); J. Wang, Heilongjiang Geomatics Ctr. of SBSM (China)

7544 3J Robust matching algorithm for image mosaic [7544-166]

L. Zeng, Harbin Institute of Technology (China) and Academy of Equipment Command and Technology (China); J. Tan, Harbin Institute of Technology (China)

7544 3K Boundary character based declining scanning-line filling algorithm [7544-336]

W. Gao, Beijing Institute of Space Mechanics \& Electricity (China) 
7544 3L Fabrication and application of diffractive optical elements (Invited Paper) [7544-359]

A. G. Poleshchuk, Institute of Automation and Electrometry (Russian Federation)

7544 3M Self-mixing interference in fiber lasers and its applications (Invited Paper) [7544-286] M. Wang, X. Dai, J. Zhou, D. Han, Y. Zhao, Nanjing Normal Univ. (China)

$75443 \mathrm{~N}$ Optoelectronic system on the base of the anamorphic element for the measuring of the elevation angles (Invited Paper) [7544-212]

I. Konyakhin, A. Merson, A. Timofeev, A. Konyakhin, Saint-Petersburg State Univ. of Information Technologies, Mechanics and Optics (Russian Federation)

754430 Electron field emission based on plasmon resonance (Invited Paper) [7544-257]

K. Iwami, A. lizuka, N. Umeda, Tokyo Univ. of Agriculture and Technology (Japan)

$75443 \mathrm{P}$ The experimental research of the systems for measuring the angle rotations and line shifts of the large aperture radio-telescope components (Invited Paper) [7544-220]

I. Konyakhin, A. Timofeev, A. Usik, D. Zhukov, Saint-Petersburg State Univ. of Information Technologies, Mechanics and Optics (Russian Federation)

$75443 Q \quad$ Tissue oxygenation and haemodynamics measurement with spatially resolved NIRS [7544-159]

Y. Zhang, Harbin Institute of Technology (China); F. Scopesi, G. Serra, Univ. of Genova (Italy); J. W. Sun, Harbin Institute of Technology (China); P. Rolfe, Harbin Institute of Technology (China), Oxford BioHorizons Ltd. (United Kingdom), and Univ. of Genova (Italy)

7544 3R Vehicle tethered aerostat optoelectronic monitoring platform system for Shanghai World EXPO [7544-177]

W. Zhou, Academy of Opto-electronics (China); Y. Wang, Beihang Univ. (China) and Academy of Opto-electronics (China); X. Han, J. Yuan, Academy of Opto-electronics (China)

$754435 \quad$ Tunable electro-optic crystal Fabry-Perot filter [7544-190]

L. Jin, E. Kondoh, Univ. of Yamanashi (Japan); K. Takizawa, Seikei Univ. (Japan)

7544 3T White trash detection of cotton lint with ultraviolet-induced fluorescence imaging method [7544-185]

F. Zhou, T. Ding, Tsinghua Univ. (China)

$75443 \mathrm{U}$ Cross-phase modulation instability in single-mode optical fibers with exponential saturable nonlinearity [7544-323]

X. Zhong, A. Xiang, Chengdu Univ. of Information Technology (China)

$75443 \mathrm{~V}$ 90-degree docking error control in polarization maintaining fiber resonator based on white-light interferometry [7544-55]

H. Lin, Q. Yao, Y. Hu, National Univ. of Defense Technology (China)

7544 3W Zernike aberration characteristics of precision conformal optical windows [7544-259]

Y. Liu, J. Ma, H. Ma, X. Jiang, Harbin Institute of Technology (China) 
$75443 X \quad$ Optical system design of a new type infrared dual-band seeker [7544-94]

M. Yongli, W. Liu, W. Wang, Changchun Univ. of Science and Technology (China)

$75443 Y \quad H i g h$ precision optical fiber fluorescent temperature measurement system and data processing [7544-162]

Y. Wang, X. Bo, F. Gui, Yanshan Univ. (China)

$75443 Z$ A design of beam shaping unit for 193nm lithography illumination system using angular spectrum theory [7544-57]

Y. Zhao, Changchun Institute of Optics, Fine Mechanics and Physics (China) and Graduate School of the Chinese Academy of Sciences (China); Y. Gong, Changchun Institute of Optics, Fine Mechanics and Physics (China); S. Li, Changchun Institute of Optics, Fine Mechanics and Physics (China) and Graduate School of the Chinese Academy of Sciences (China); W. Zhang, Changchun Institute of Optics, Fine Mechanics and Physics (China)

754440 Design of micro-sensor-array detector for toxic gas [7544-281]

H. Liao, P. Tian, National Key Lab. of Fundamental Science of Micro/Nano-Device and System Technology (China) and Chongqing Univ. (China)

754441 Design of off-axis three-mirror system with Zernike surface [7544-73]

G. Gong, J. Wei, Shanghai Institute of Technological Physics (China); W. Shen, Soochow Univ. (China)

754442 Mechanism analysis on biofouling detection based on optical fiber sensing technique [7544-250]

H. Ma, F. Yuan, Y. Liu, X. Jiang, Harbin Institute of Technology (China)

754443 Investigation on fiber laser vector hydrophone: theory and experiment [7544-88]

W. Zhang, F. Zhang, R. Ma, F. Li, Y. Liu, Institute of Semiconductors (China)

754444 Suppression of relaxation oscillation in strong optical injection-locked semiconductor laser diode [7544-244]

X. Fang, Ningbo Univ. of Technology (China) and Gannan Normal Univ. (China); W. Li, Ningbo Univ. of Technology (China) and Ningbo Univ. (China); J. Bao, Ningbo Univ. of Technology (China); T. Xu, Ningbo Univ. (China); H. Yan, Ningbo Univ. of Technology (China) and Taiyuan Univ. of Technology (China)

\section{LASER MEASUREMENT TECHNIQUES AND INSTRUMENTS}

754445 Measurements of absolute long distances (Invited Paper) [7544-213]

F. Pollinger, N. R. Doloca, K. Meiners-Hagen, M. Wedde, A. Abou-Zeid, PhysikalischTechnische Bundesanstalt (Germany)

754446 Metrological AFMs and its application for versatile nano-dimensional metrology tasks (Invited Paper) [7544-344]

G. Dai, T. Dziomba, F. Pohlenz, H.-U. Danzebrink, L. Koenders, Physikalisch-Technische Bundesanstalt (Germany) 
754447 Two-modality laser diode interferometer for high-accuracy measurement of long-range absolute distance (Invited Paper) [7544-235]

B. Wang, Shanghai Institute of Optics and Fine Mechanics (China) and Graduate School of the Chinese Academy of Sciences (China); Z. Li, X. Wang, P. Bu, Shanghai Institute of Optics and Fine Mechanics (China)

754448 Sensitive elastic modulus mapping of micro-structured biomaterials (Invited Paper) [7544-15]

J. Y. Sun, Jilin Univ. (China); X. Liu, The Univ. of Warwick (United Kingdom); J. Tong, Jilin Univ. (China); Z. Y. Yue, The Univ. of Warwick (United Kingdom)

754449 Thin film thickness and refractive index measurement by multiple beam interferometry and fast spectral correlation method [7544-172]

T. Y.-F. Chen, C.-C. Chen, National Cheng Kung Univ. (Taiwan)

7544 4A Preparation and photoluminescence properties of $\mathrm{Er}^{3+}$-doped silicate glasses [7544-120]

Z. Song, Liaoning Shihua Univ. (China)

7544 4B Widely continuous-tuning single-wavelength laser based on commercial multimode VCSELs [7544-273]

T.-C. Yen, C.-P. Hsu, Y.-H. Wu, National Sun Yat-Sen Univ. (Taiwan); D.-L. Cheng, Shu-Te Univ. (Taiwan); W.-C. Kuo, National Sun Yat-Sen Univ. (Taiwan)

7544 4C Rapid inspection for sub-wavelength line-width [7544-45]

M.-C. Chang, C.-Y. Chen, Chung Yuan Christian Univ. (Taiwan); H.-C. Liou, Industrial Technology Research Institute (Taiwan)

7544 4D The measurement of bicycle exercising energy transfer [7544-349]

H.-P. Cho, National Taiwan Univ. (Taiwan); Z.-J. Jian, C.-S. Jwo, National Taipei Univ. of Technology (Taiwan); J.-Y. Wang, S.-L. Chen, National Taiwan Univ. (Taiwan)

7544 4E Fine correction of nonlinearity in homodyne interferometry [7544-1 18]

P. Hu, Harbin Institute of Technology (China); F. Pollinger, K. Meiners-Hagen, PhysikalischTechnische Bundesanstalt (Germany); H. Yang, Harbin Institute of Technology (China);

A. Abou-Zeid, Physikalisch-Technische Bundesanstalt (Germany)

$75444 \mathrm{~F}$ Study of instrument measurement of carbon monoxide concentration by absorption spectrum [7544-267]

J. Guo, L. Wang, Z. Wang, J. Li, Southwest Jiaotong Univ. (China)

7544 4G Straightness inspecting system for long shaft based on cross laser [7544-271]

Z. Chang, L. Pang, Y. Yang, Dalian Nationalities Univ. (China)

$75444 \mathrm{H} \quad$ Comparison of two methods used for calculating backscattering Mueller matrix from turbid media [7544-71]

H.-W. Zhang, H.-H. Jia, S.-L. Chang, H.-L. Zhang, J.-C. Yang, National Univ. of Defense Technology (China)

75444 Optical error of cat's eye retro-reflector and its correction [7544-335]

S. Zhao, Hebei Polytechnic Univ. (China); G. Zhang, Tianjin Univ. (China) 
7544 4J Temperature compensation for RLG based on neural network [7544-70]

P. Yang, Y. Qin, J. You, Northwestern Polytechnical Univ. (China)

7544 4K Design and realization of controllable measuring force profilometer [7544-324]

W. Pan, Huazhong Univ. of Science and Technology (China); S. Wang, Luoyang Institute of Science and Technology (China); S. Chang, Huazhong Univ. of Science and Technology (China)

$75444 \mathrm{~L} \quad$ Effect of pressure on methane absorption characteristic in IR region [7544-263] M. Kong, S. Chen, J. Zhao, China Jiliang Univ. (China)

7544 4M Pulsed time-of-flight laser scanning techniques for industrial safety monitoring applications [7544-89]

Z. Sun, Laser Institute of Shandong Academy of Sciences (China); J. Deng, Beijing Institute of Technology (China); C. Wang, Laser Institute of Shandong Academy of Sciences (China); C. Liu, Tianjin Univ. (China)

7544 4N Attenuation of laser generated SAWs in heated PMMA material [7544-142] J. Li, J. Liu, L. Dong, Z. Shen, L. Yuan, Nanjing Univ. of Science and Technology (China)

754440 Surface damage effect detection of sensor in optical lens based on cat-eye effect [7544-81] Y. Zhao, H. Sun, Academy of Equipment Command and Technology (China); S. Gu, China Jiu Quan Satellite Launch Ctr. (China); P. Fan, Academy of Equipment Command and Technology (China)

7544 4P Analysis of telescope coupling efficiency for all-fiber spectroscopic Raman lidar [7544-224] S. Li, D. Hua, Y. Wang, L. Wang, J. Liu, P. Wang, Xi'an Univ. of Technology (China)

$75444 Q \quad$ Research on 2D laser distance sensor [7544-192]

J. Ren, X. Gao, J. Peng, J. Guo, Southwest Jiaotong Univ. (China)

\section{Part Three}

7544 4R Design of control system for stabilization output power of diode-pumped single frequency Nd:YAG laser at 1064nm [7544-206]

Y. Zheng, M. Jiao, J. Xing, W. Wang, Xi'an Univ. of Technology (China)

7544 4S Internal optical feedback effect in fiber ring laser [7544-97]

J. Zhou, Y. Ge, Nanjing Univ. of Information Science and Technology (China)

7544 4T Precise measurement of liquid petroleum tank volume based on data cloud analysis [7544-160]

J. Wang, Z. Liu, L. Zhang, L. Guo, X. Bao, L. Tong, National Institute of Metrology (China)

$75444 \mathrm{U}$ A real-time measurement system for parameters of live biology metabolism process with fiber optics [7544-346]

W. Tao, H. Zhao, Z. Liu, J. Cheng, R. Cai, Shanghai Jiaotong Univ. (China) 
$75444 \mathrm{~V} \quad$ Measurement of transient wavelength and line-width of DFB diode laser by delayed self-heterodyne interferometer [7544-303]

J. Liu, Tianjin Univ. (China) and North China Institute of Aerospace Engineering (China);

Z. Du, Tianjin Univ. (China); Y. An, Tianjin Univ. (China) and Hebei Polytechnic Univ. (China);

J. Li, D. Gao, K. Xu, Tianjin Univ. (China)

7544 4W Dynamic MEMS characterization system using differential phase measurement method [7544-02]

T. Guo, Z. Wu, L. Ma, X. Fu, X. Hu, Tianjin Univ. (China)

7544 4X 3D profile measurement using heterodyne dual-frequency phase shift method [7544-140] F. Duan, N. LV, X. Lou, P. Sun, Beijing Information Science and Technology Univ. (China)

$75444 \mathrm{Y}$ Precision control of scale using in industrial close-range photogrammetry [7544-249]

X. Guo, J. Liang, Z. Xiao, B. Cao, Xi'an Jiaotong Univ. (China)

$75444 Z$ Clearance measurement of commercial slider/disk with a symmetrical common-path heterodyne interferometry [7544-318]

N. Song, Y. Meng, Tsinghua Univ. (China)

754450 Optimum design and experimental study of tunable dual-frequency Nd:YAG laser with large frequency difference [7544-158]

J. Xing, M. Jiao, Y. Liu, L. Chen, Xi'an Univ. of Technology (China)

$754451 \quad$ Measurement of velocity distribution of Laser-generated Rayleigh wave on welded structure [7544-245]

L. Dong, C. Ni, Z. Shen, X. Ni, Nanjing Univ. of Science \& Technology (China)

754452 Implementation of pulse position modulated blue-green laser communication system [7544-294]

T. Xu, X. Sun, D. Wen, Navy Submarine Academy (China)

INSTRUMENT AND MEASUREMENT SYSTEM CALIBRATION

754453 Measurement in precision engineering (Invited Paper) [7544-27]

H. Bosse, Physikalisch-Technische Bundesanstalt (Germany)

754454 Invasive and non-invasive measurement in medicine and biology: calibration issues (Invited Paper) [7544-121]

P. Rolfe, Harbin Institute of Technology (China), Oxford BioHorizons Ltd. (United Kingdom), and Univ. of Genova (Italy); Y. Zhang, J. Sun, Harbin Institute of Technology (China); F. Scopesi, G. Serra, Univ. of Genova (Italy); K. Yamakoshi, S. Tanaka, T. Yamakoshi, Y. Yamakoshi, M. Ogawa, Kanazawa Univ. (Japan)

754455 Dynamic error measurement of force sensors: toward the dynamic calibration and correction (Invited Paper) [7544-356]

Y. Fujii, K. Maru, Gunma Univ. (Japan)

754456 Application of DVD pick-up head for vibration measurement of NB fan [7544-207] C.-L. Chu, Y.-C. Liu, Southern Taiwan Univ. (Taiwan) 
754457 Testing unit for laser rangefinder [7544-299]

E. V. Kuvaldin, A. G. Ershov, V. F. Zakharenkov, V. M. Polyakov, L. N. Arhipova, The Russian Federation State Scientific and Manufacturing Corp. (Russian Federation)

754458 Independent distortion correction algorithm for machine vision systems [7544-241]

T. Wei, Y. Dong, Harbin Institute of Technology (China)

754459 Method for reducing harmonic wave voltage of digital synthetic sine wave [7544-266]

B. Wang, M. Yan, P. Pan, W. Feng, Beijing Orient Institute of Measurement and Test (China)

7544 5A Performance of fuel system at different diesel temperature [7544-246]

X. XU, X. Li, Z. Sun, China Jiliang Univ. (China)

7544 5B Testing error analysis of accelerometer error model coefficients on indexing table [7544-13]

S. Ren, Y. Wang, Y. Cheng, S. Chen, Harbin Institute of Technology (China)

7544 5C Temperature characteristics for PTC material heating diesel fuel [7544-289]

L. GU, X. Li, J. Wang, Y. Li, M. Li, China Jiliang Univ. (China)

$75445 \mathrm{D}$ Study on correcting the temperature measurement of infrared thermography by determining the atmospheric transmittance [7544-84]

J. Wu, J. Sun, L. Chen, China Jiliang Univ. (China)

$75445 \mathrm{E}$ Instrument for bearing fault diagnosis based on demodulated resonance technology [7544-74]

Y. LU, X. Hu, Y. Zheng, China Jiliang Univ. (China)

$75445 \mathrm{~F} \quad$ Analysis of blade vibration frequencies from blade tip timing data [7544-95]

M. Li, F. Duan, T. Ouyang, Tianjin Univ. (China)

7544 5G Contrasting study of on-line calibration technology for robot coordinate measurement system [7544-328]

$X$. Yang, T. YU, Y. Guo, S. Ye, Tianjin Univ. (China)

$75445 \mathrm{H} \quad$ Calibration and compensation of dual sensor system used in ultra precision diameter and form measuring instrument [7544-175]

Y. Wu, China Jiliang Univ. (China); Z. Xue, W. Zhan, National Institute of Metrology (China)

$75445 \mathrm{C} \quad$ Calibration of 3D laser measurement system based on projective transformation [7544-148]

Y. Guo, Y. Du, Z. Du, Z. Yao, Shanghai Jiao Tong Univ. (China)

$75445 \mathrm{~J}$ Detection of positional precision of NC motorized stage based on photoelectric autocollimator [7544-131]

B. Yan, Beijing Information Science and Technology Univ. (China); Q. Tan, Beijing Univ. of Posts and Telecommunications (China); N. Lv, Beijing Information Science and Technology Univ. (China)

7544 5K Probe parameters calibration for articulated arm coordinate measuring machine [7544-64] W. Cheng, Y. Fei, L. Yu, R. Yang, Hefei Univ. of Technology (China) 
$75445 \mathrm{~L} \quad$ Dynamic test of radio altimeter based on IQ modulation [7544-351]

H. Pan, Y. Tian, M. Li, The 92941st Unit of PLA (China)

$75445 \mathrm{M}$ Transfer alignment design and experiment evaluation of the SINS for GMLRS artillery rocket [7544-214]

J. You, Y. Qin, J. Xia, P. Yang, G. Yan, Northwestern Polytechnical Univ. (China); Y. Song, Northwestern Polytechnical Univ. (China) and Sichuan Aerospace Industry Corp. (China); Y. Fu, Sichuan Aerospace Industry Corp. (China)

$75445 \mathrm{~N} \quad$ Measuring instrument for radial composite deviations of high-precision master gear [7544-320]

Y. Ma, T. Wang, Z. Lou, L. Wang, Dalian Univ. of Technology (China); Y. Zhang, Changchun Institute of Optics, Fine Mechanics and Physics (China)

754450 Measurement of center of rotation for projection in x-ray two-dimensional computed tomography system [7544-18]

B. Li, The First Research Institute of Ministry of Public Security (China) and Peking Univ. (China); Y. Zhang, Y. Mo, The First Research Institute of Ministry of Public Security (China)

7544 5P Calibration of three-axis magnetometer diversionary error based on equipment and LMS adaptive algorithm [7544-44]

H. Pang, S. Luo, M. Pan, Q. Zhang, R. Xie, National Univ. of Defense Technology (China)

7544 5Q Modeling of CMM dynamic error based on optimization of neural network using genetic algorithm [7544-219]

Q. Ying, L. Zai, L. Yi, China Jiliang Univ. (China)

$75445 R$ Calibration of absolute radial dimension of measurement for cylindrical coordinate measuring machine [7544-290]

Z. Zhao, G. Wang, H. Zhao, B. Li, Zhongyuan Univ. of Technology (China)

754455 Radiometric calibration of frame transfer CCD camera with uniform source system [7544-139]

J. Zhou, R. Shi, Y. Chen, Y. Zhou, W. Shen, Soochow Univ. (China) and Jiangsu Key Lab. of Modern and Optical Technology (China)

$75445 T \quad$ Distortion model for star tracker [7544-21]

H. Liu, Y. Tan, National Univ. of Defense Technology (China); D. Sheng, Wuhan Ordnance Non-commissioned Officers Academy (China); J. Yang, National Univ. of Defense Technology (China) and National Lab. of Space Intelligent Control (China); J. Tan, W. Wang, D. Su, National Univ. of Defense Technology (China)

$75445 \mathrm{U}$ Application of laser sensors for on-line calibration of displacement transducers [7544-60] J. Xie, National Institute of Metrology (China) and China Jiliang Univ. (China); H. Gao, X. Ye, F. Gu, National Institute of Metrology (China); D. Li, China Jiliang Univ. (China)

7544 5V Error compensation for truck scale based on complex BP neural networks [7544-101] H. Lin, Polytechnic College of Hunan Normal Univ. (China); Z. Teng, R. Liu, D. Zheng, Hunan Univ. (China); J. Yang, Polytechnic College of Hunan Normal Univ. (China) 
7544 5W Parameter identification of double parallel joints coordinate measuring machine [7544-116] T. Ye, J. Li, W. Cheng, L. Yu, Y. Fei, Hefei Univ. of Technology (China)

$75445 X \quad$ Characterization scattering parameters of coaxial air-lines by physical measurements [7544-269]

H. Liang, Beijing Orient Institute of Measurement and Test (China)

7544 5Y Quasi-static calibration of piezoelectric sensor using half-sine pressure pulse [7544-184] Q. Zhang, Nanjing Univ. of Science and Technology (China) and Nanjing Institute of Technology (China); F. Shang, D. Kong, Nanjing Univ. of Science and Technology (China)

$75445 Z$ Thermal deformation of helical gears [7544-208]

Y. Zhang, Y. Fei, S. Liu, Hefei Univ. of Technology (China)

MEMS AND NANOMETER MEASUREMENT

754460 Proposal of a new Zeeman slower for fabrication of nano-scale length standards (Invited Paper) [7544-354]

W. Wu, Y. Ma, Y. Xiao, P. Zhang, Tongji Univ. (China)

754461 Advanced optical techniques for the measurement of the internal geometry of MEMS structures (Invited Paper) [7544-221]

W. Sun, R. K. Leach, National Physical Lab. (United Kingdom)

754462 Size and mass loading effect on quality factor of single-crystal silicon cantilever in atmosphere [7544-65]

Y. Liv, G. Zhao, Y. Chen, J. Chu, Univ. of Science and Technology of China (China)

754463 Directional design of optical lens based on metallic nano-slits with variant widths [7544-189]

Q. Zhu, Y. Zhang, Capital Normal Univ. (China)

754464 Determining the Young's modulus of SU-8 negative photoresist through tensile testing for MEMS applications [7544-325]

J. Gao, L. Guan, J. Chu, Dalian Univ. of Technology (China) and Key Lab. for Micro/Nano Technology and System of Liaoning Province (China)

754465 Superhydrophobicity of post-like aligned carbon nanotube films [7544-37]

L. Gang, East China Jiaotong Univ. (China)

$754466 \quad$ FMPS measurement of nanoparticle pollutant in office air [7544-203]

Z. Yin, J. Lin, M. Yu, China Jiliang Univ. (China)

754467 Quantum simulation of laser cooling for fabrication of nanometer scale pitch standard [7544-355]

Y.-L. Xiao, Y. Ma, W. Wu, W.-G. Gong, T.-B. Li, Tongji Univ. (China)

754468 Temperature-frequency characteristics of silicon micro-cantilever and measurement techniques in high temperature environment [7544-251]

D. She, X. Wang, X. Zhang, L. Wang, Dalian Univ. of Technology (China) 
754469 Measurement of diffusive motion of micro-fluidic particles by Micro-PIVPTV technique [7544-138]

M. Yang, H.-L. Wang, W. Han, College of Metrological Technology and Engineering (China)

75446 A Characterization of surface/subsurface damage for ceramics with nanoindentation method [7544-228]

Y. Bao, G. Chai, S. Gu, Zhejiang Univ. of Technology (China)

7544 6B Parameters of hot embossing in microfluidic chips [7544-239]

W. Wang, S. Li, L. Tian, J. Li, T. Qin, X. Liu, Harbin Institute of Technology (China)

7544 6C Modeling and simulation of through-focus images for dimensional analysis of nanoscale structures [7544-28]

X. Chen, S. Liu, C. Zhang, Y. Ma, J. Zhu, Huazhong Univ. of Science and Technology (China)

\section{ACCURACY THEORY AND UNCERTAINTY ANALYSIS}

7544 6D Process capability indices and risk analysis for circular position tolerance zones (Invited Paper) [7544-230]

M. P. Krystek, Physikalisch-Technische Bundesanstalt (Germany)

$75446 \mathrm{E}$ Methods of data processing and estimation of measuring accuracy in stereoscopic system for the control of objects displacements (Invited Paper) [7544-14]

K. G. Arakantsev, D. V. Zhukov, I. A. Konyakhin, Saint-Petersburg State Univ. of Information Technologies, Mechanics and Optics (Russian Federation)

$75446 \mathrm{~F} \quad$ Uncertainty evaluation for calibration of optical fiber length standard using time-of-flight method [7544-302]

X. Huang, G. Xu, National Metrology Ctr., A*STAR (Singapore); D. L. Wang, Nanyang Technological Univ. (Singapore)

7544 6G Development of 3D touch trigger probe with real-time observation [7544-211] C.-L. Chu, C.-Y. Wu, Southern Taiwan Univ. (Taiwan)

7544 6H Dual-observation adjustment model of large control network for underground [7544-122] H.-F. Bian, China Univ. of Mining and Technology (China) and Jiangsu Key Lab. of Resource and Environmental Information Engineering (China); S. Zhang, China Univ. of Mining and Technology (China); Q. Zhang, China Univ. of Mining and Technology (China) and Jiangsu Key Lab. of Resource and Environmental Information Engineering (China)

$754461 \quad$ Accuracy analysis of distributed simulation systems [7544-58]

Q. Lin, J. Guo, The Academy of Equipment Command and Technology (China)

$75446 \mathrm{~J}$ Uncertainty analysis in measurement for LED junction temperature and thermal resistance [7544-51]

H. Shen, X. Zhou, W. Zhang, M. Liu, Fudan Univ. (China)

7544 6K Theoretical and experimental research on machine tool servo system for ultra-precision position compensation on CNC lathe [7544-229]

Z. Ma, L. Hu, H. Zhao, B. Wu, Z. Peng, X. Zhou, H. Zhang, S. Zhu, L. Xing, H. Hu, Jilin Univ. (China) 
$75446 \mathrm{~L} \quad$ New intelligent power quality analyzer and dynamic uncertainty research [7544-198] $X$. Feng, Hefei Univ. of Technology (China) and Anhui Univ. of Technology (China); J. Zhang, Anhui Univ. of Technology (China); Y. Fei, Hefei Univ. of Technology (China)

7544 6M Application of ellipsoid optimization algorithm and state feedback control in ellipsoidal parametric uncertainty system [7544-268]

D. Tang, X. Meng, D. Wang, Nanjing Univ. of Aeronautics and Astronautics (China)

$75446 \mathrm{~N}$ Application of Monte Carlo method for analyzing reference involute's measurement accuracy [7544-104]

Z. Lou, Key Lab. for Precision and Non-traditional Machining of Ministry of Education (China);

L. Wang, Key Lab. for Micro/Nano Technology and System of Liaoning Province (China)

754460 Geometrical error correction research in high precision 2D laser measuring instrument [7544-196]

X. Zhang, China Jiliang Univ. (China); Z. Xue, H. Wang, National Institute of Metrology

(China)

7544 6P Mobile large scale 3D coordinate measuring system based on network of rotating laser automatic theodolites [7544-308]

Z. Liu, Z. Liu, J. WU, Y. XU, Xi'an Jiaotong Univ. (China)

$75446 \mathrm{Q} \quad \mathrm{CNC}$ test approach based on simulation model of machine tool [7544-96]

F. Chen, D. Fan, L. Zhang, M. Du, National Univ. of Defense Technology (China)

7544 6R Error analysis of mast mounted electro-optical stabilized platform based on multi-body kinematics theory [7544-317]

X. Zhou, D. Ma, D. Fan, Z. Zhang, National Univ. of Defense Technology (China)

7544 6S Categorical data model for cylindricity consistent with geometrical product specifications standard system [7544-40]

W. LU, X. Liu, Huazhong Univ. of Science and Technology (China); X. Jiang, Univ. of Huddersfield (United Kingdom) and Huazhong Univ. of Science and Technology (China); Q. Qi, Huazhong Univ. of Science and Technology (China); P. Scott, Univ. of Huddersfield (United Kingdom)

$75446 \mathrm{~T} \quad$ Comparative study of immune algorithm and genetic algorithm in thinned rectangular array synthesizing [7544-232]

J. Zhang, Harbin Engineering Univ. (China) and Northeast Forestry Univ. (China); W. Pang, Harbin Engineering Univ. (China)

$75446 \mathrm{U}$ Comprehensive analysis of factors impacting on output signal of EFPI fiber-optic sensor [7544-41]

W. Wang, Dalian Univ. of Technology (China) and Guangdong Ocean Univ. (China); Q. YU, Q. Wang, X. Zhou, Dalian Univ. of Technology (China) 
$75446 \mathrm{~V}$ A new design of high precision differential plane mirror interferometer (Invited Paper) [7544-53]

W. Hou, Univ. of Shanghai for Science and Technology (China)

7544 6W Design and simulation of whole closed-loop algorithm for motion platform control for automated optical inspection [7544-151]

Z. Fang, China Jiliang Univ. (China); D. Chen, Ningbo Entry-Exit Inspection and Quarantine Bureau (China); X. Wang, S. Yang, China Jiliang Univ. (China)

7544 6X Modeling of pan-tilt-zoom cameras for tracking measurement [7544-20]

Y. Shi, R.-S. Lu, N. Chen, R. Xia, Hefei Univ. of Technology (China)

$75446 \mathrm{Y}$ Study on optical energy band gap of $\mathrm{SrBi}_{2} \mathrm{Ta}_{2} \mathrm{O}$, thin films annealed in a $\mathrm{H}_{2}$-contained ambient [7544-61]

D. Wang, Nanjing Univ. of Aeronautics and Astronautics (China); T. Yu, D. Wu, A. Li, A. Hu, Z. Liu, Nanjing Univ. (China)

$75446 Z$ Measurement and research on improving the performance of dual-temperature refrigerator system [7544-182]

C.-S. Jwo, M.-W. Lin, C.-Y. Lin, C.-W. Hsu, National Taipei Univ. of Technology (Taiwan);

S.-L. Chen, National Taiwan Univ. (Taiwan)

754470 An AOI approach for IC lead index auto-verification [7544-333]

D.-B. Perng, G.-C. Chang, S.-M. Lee, S.-H. Chen, National Chiao Tung Univ. (Taiwan)

754471 Measurement of optical glass refractive index free from effect of environmental temperature [7544-31]

J. Ma, Q. Hao, Q. Zhu, Y. Hu, X. Cheng, Beijing Institute of Technology (China)

754472 Separation of tilt errors from measured data of aspheric surface without datum [7544-330] D. Xie, H. YU, J. XU, Changchun Univ. of Science and Technology (China); H. Han, Air Force Aviation Univ. (China); Y. XU, T. Liu, Changchun Univ. of Science and Technology (China)

754473 Design of second-order sliding mode tracking differentiator to reduce noise perturbation [7544-350]

B. Zhao, N. Qi, Harbin Institute of Technology (China)

754474 Radiation signature of clouds [7544-68]

G. Yuan, Z. Fan, X. Sun, Harbin Institute of Technology (China)

754475 Algorithm for fast location of circle center based on statistical method [7544-129]

T. Ji, X. YU, Harbin Univ. of Science and Technology (China)

754476 Relationship between crack defects in magnetic tiles and variation frequencies of highorder vibration mode based on modal technology [7544-173]

L. Fu, S. Yang, X. Wang, D. Hou, China Jiliang Univ. (China)

Author Index 


\title{
Conference Committees
}

\author{
Honorary Chairs
}

Guofan Jin, Tsinghua University (China)

Tongbao Li, Tongji University (China)

Zhonghua Zhang, NIM (China)

Jie Gao, Sichuan University (China)

Shenghua Ye, Tianjin University (China)

Yuri V. Chugui, TDI SIE, Siberian Branch of the Russian Academy of Sciences (Russian Federation)

Zhu Li, Huangzhong University of Science and Technology (China)

Guoxiong Zhang, Tianjin University (China)

Ahmed Abou-zeid, Physikalisch-Technische Bundesanstalt (Germany)

Peter Rolfe, Università degli Studi di Genova (Italy)

Konrad Herrmann, Physikalisch-Technische Bundesanstalt (Germany)

Chao-Kuang Chen, National Cheng Kung University (China)

Program Committee

Chair

Jiubin Tan, Harbin Institute of Technology (China)

Cochairs

Yetai Fei, Hefei University of Technology (China)

Tony Wilson, University of Oxford (United Kingdom)

Harald Bosse, Physikalisch-Technische Bundesanstalt (Germany)

Min Gu, Swinburne University of Technology (Australia)

Kuang-Chao Fan, National Taiwan University (Taiwan, China)

Seung-Woo Kim, KAIST (Korea, Republic of)

Wei Gao, Tohoku University (Japan)

Members

Shulian Zhang, Tsinghua University (China)

Igor A. Konyakhin, Saint-Petersburg State University of Information

Technologies, Mechanics and Optics (Russian Federation)

Norihiro Umeda, Tokyo University of Agriculture and Technology

(Japan)

Richard Leach, National Physical Laboratory (United Kingdom)

Yusaku Fujii, Gunma University (Japan)

Xianping Liu, University of Warwick (United Kingdom)

Patrick S. P. Wang, Northeastern University (United States)

Chenggen Quan, National University of Singapore (Singapore) 
Otto Jusko, Physikalisch-Technische Bundesanstalt (Germany)

Francesco Righini, Istituto Nazionale di Ricerca Metrologica (Italy)

Hou Wenmei, University of Shanghai for Science and Technology

(China)

Michael Krystek, Physikalisch-Technische Bundesanstalt (Germany)

Dalwoo Kim, Research Institute of Industrial Science (Korea, Republic

of)

Liangchi Zhang, University of New South Wales (Australia)

Michael Neugebauer, Physikalisch-Technische Bundesanstalt (Germany)

Derek Chetwynd, University of Warwick (United Kingdom)

Rudolf Tracht, Universität Duisburg-Essen (Germany)

P. H. J. Schellekens, Eindhoven University of Technology (Netherlands)

Gaoliang Dai, Physikalisch-Technische Bundesanstalt (Germany)

Satoshi Kiyono, Tohoku University (Japan)

J. F. Song, NIST (United States)

Senyung Lee, National Cheng Kung University (China)

Kiyoshi. Takamasu, University of Tokyo (Japan)

Rongqing Lin, National Taiwan University (China)

Ulrich Neuschaefer-Rube, Physikalisch-Technische Bundesanstalt (Germany)

Guobiao Wang, National Natural Science Foundation of China (China)

Liying Wu, Harbin Institute of Technology (China)

$X$. Jiang, University of Huddersfield (United Kingdom)

Tien-I. Liu, California State University, Sacramento (United States)

Organizing Committee

Chair

Jianzhong Lin, China Jiliang University (China)

Cochairs

Yongsheng Gao, University of Science and Technology (China)

Xinghua Qu, Tianjin University (China)

Lijiang Zeng, Tsinghua University (China)

Jiaru Chu, University of Science and Technology of China (China)

Tianquan Fan, Institute of Optics and Electronics (China)

Zhenghui Zhu, China Academy of Launch Vehicle Technology (China)

Zili Zhou, Changcheng Institute of Metrology and Measurement (China)

Zhaoyao Shi, Beijing University of Technology (China)

Dongsheng Li, China Jiliang University (China) 
Members

Yuchi Lin, Tianjin University (China)

Qibo Feng, Beijing Jiaotong University (China)

Shuliang Ye, China Jiliang University (China)

Yinhan Gao, Jilin University (China)

Junjie Guo, Xi'an Jiaotong University (China)

Jian Zhang, Harbin Institute of Technology (China)

Donglin Peng, Chongqing University of Technology (China)

Jianhua Wang, Xi'an Technological University (China)

Yueke Wang, National University of Defense Technology (China)

Yan Li, Tsinghua University (China)

Xiaogang Sun, Harbin Institute of Technology (China)

Linna Zhang, Zhengzhou University (China)

Xiangzhao Wang, Shanghai Institute of Optics and Fine Mechanics (China)

Xiaoyang Yu, Harbin University of Science and Technology (China)

Guoyu Zhang, Changchun University of Science and Technology (China)

Yinxiao Miao, Beijing Aerospace Institute of Metrology and Measurement (China)

Yongying Yang, Zhejiang University (China)

Zhongyu Wang, Beihang University (China)

Lianqing Zhu, Beijing Information Science \& Technology University (China)

Qun Hao, Beijing Institute of Technology (China)

Hui Zhao, Shanghai Jiaotong University (China)

Xiaodong Wang, Dalian University of Technology (China)

Junbi Liao, Sichuan University (China)

Yingjie Yu, Shanghai University (China)

Rongsheng Lu, Hefei University of Technology (China)

Jingmin Dai, Harbin Institute of Technology (China)

Yong Xu, Changcheng Institute of Metrology \& Measurement (China)

Weiqian Zhao, Beijing Institute of Technology (China)

Tiehua Ma, North University of China (China)

Zhiquan Li, Yanshan University (China)

Yongrui Zhao, China University of Petroleum (China)

Zhihong Liu, China Aerospace Science and Technology Corporation (China)

Mingxing Jiao, Xi'an University of Technology (China)

Jinwei Sun, Harbin Institute of Technology (China)

Yanqiu Li, Beijing Institute of Technology (China) 
Secretaries General

Xianfang Wen, Harbin Institute of Technology (China)

Peng Jin, Harbin Institute of Technology (China)

Deputy Secretary General

Xiping Zhao, Harbin Institute of Technology (China)

Secretaries

Jie Lin, Harbin Insitute of Technology (China)

Yue Gao, Harbin Institute of Technology (China)

Ci'en Zhong, Harbin Institute of Technology (China)

\section{Session Chairs}

1 Modern Optics and Instruments for Precision Measurement

Liang-Chia Chen, National Taipei University of Technology (Taiwan, China)

Kentaro Iwami, Tokyo University of Agriculture and Technology (Japan)

2 Instrumentation Theory and Methodology

Richard Leach, National Physical Laboratory (United Kingdom)

Ming Wang, Nanjing Normal University (China)

3 Measurement for Precision and Ultra-Precision Machining 1

Kuang-chao Fan, National Taiwan University (Taiwan, China)

$4 \quad$ Novel Instrument and Measurement System 1

Derek G. Chetwynd, University of Warwick (United Kingdom)

Zhaoyao Shi, Beijing University of Technology (China)

5 Sensors, Converters, and Control System

Shulian Zhang, Tsinghua University (China)

6 Optoelectronic System and Optical Instruments Design 1

Ming Wang, Nanjing Normal University (China)

Xuebo Huang, National Metrology Centre, Agency for Science,

Technology and Research (Singapore)

$7 \quad$ Measurement for Precision and Ultra-Precision Machining 2

P. Coppa, Università degli Studi di Roma Tor Vergata (Italy)

$8 \quad$ Novel Instrument and Measurement System 2

Kenichi Yamakoshi, Kanazawa University (Japan)

Shinobu Tanaka, Kanazawa University (Japan) 
9 Laser Measurement Techniques and Instruments 1

Ahmed Abou-Zeid, Physikalisch-Technische Bundesanstalt (Germany) Wenmei Hou, University of Shanghai for Science and Technology

(China)

10 Instrument and Measurement System Calibration

Peter Rolfe, Università degli Studi di Genova (Italy)

Yusaku Fujii, Gunma University (Japan)

11 Measurement for Precision and Ultra-Precision Machining 3

O. Jusko, Physikalisch-Technische Bundesanstalt (Germany)

Wei Gao, Tohoku University (Japan)

12 MEMS and Nanometer Measurement 1

Xianping Liu, University of Warwick (United Kingdom)

Peng Jin, Harbin Institute of Technology (China)

13 Laser Measurement Techniques and Instruments 2

Yan Zhang, Capital Normal University (China)

14 Optoelectronic System and Optical Instruments Design 2

Weihu Zhou, Academy of Opto-electronics (China)

Peter Rolfe, Università degli Studi di Genova (Italy)

15 Accuracy Theory and Uncertainty Analysis

Michael P. Krystek, Physikalisch-Technische Bundesanstalt (Germany)

Dongsheng Li, China Jiliang University (China)

16 MEMS and Nanometer Measurement 2

Gaoliang Dai, Physikalisch-Technische Bundesanstalt (Germany)

Xianping Liu, University of Warwick (United Kingdom) 
Downloaded From: https://www.spiedigitallibrary.org/conference-proceedings-of-spie on 26 Apr 2023

Terms of Use: https://www.spiedigitallibrary.org/terms-of-use 


\section{Congratulations on the Convocation of ISPEMI 2010}

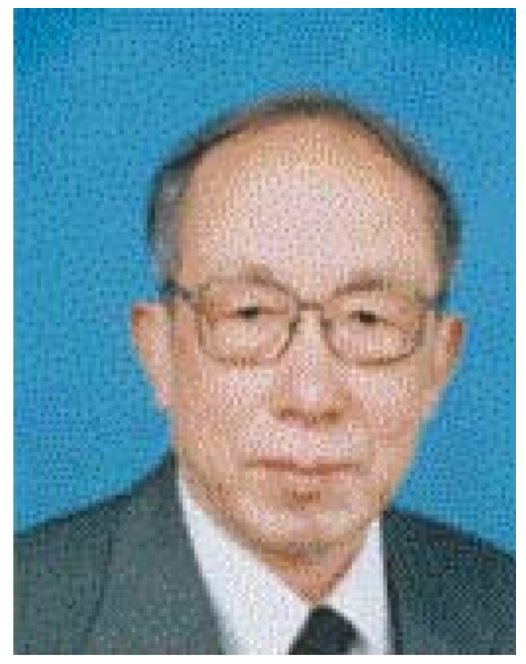

It is my honor, on behalf of the International Committee on Measurements and Instrumentation (ICMI), to warmly congratulate the successful convocation of the 6th International Symposium on Precision Engineering Measurements and Instrumentation in Hangzhou, China.

The International Committee on Measurements and Instrumentation (ICMI) was established during the Second International Symposium on Measurement Technology and Intelligent Instruments, ISMTII'93, in Wuhan, China. Since then ICMI has organized a series of ISMTII symposia around the world: Hayama, Japan (1996), Miskolc Lillafured, Hungary (1998), Giza Cairo, Egypt (2001), Hong Kong, China (2003), Huddersfeld, UK (2005), Sendai, Japan (2007), and Saint-Petersburg, Russia (2009).

While symposia of ISMTII were being held in the rest of the world, another series of symposia, ISIST (International Symposium on Instrumentation Science and Technology) were held in China. The first symposium of ISIST, organized by Prof. J. B. Tan and Prof. Y. T. Fei, was held in Luoyang, China in 1999, as many scholars expressed their wish to attend the symposium in China. The second symposium, ISIST 2002, and First International Symposium on Precision Mechanical Measurement ISPMM 2002, were held in Jinan and Hefei, respectively. Therefore, ICMI has three series of symposia: ISMTII, ISIST, and ISPMM.

In order to make the subject areas of ISIST and ISPMM more precise, specific, and interdisciplinary, the organizing committees decided to combine them into one, and under the suggestion from the General Secretary of ICMI Prof. Yongsheng Gao, refer to it as International Symposium on Precision Engineering Measurements and Instrumentation (ISPEMI) from 2010 onward.

Precision Engineering Measurements and Instrumentation are closely related multidisciplinary fields and instrumentation science could create versatile instruments for precision measurements.

Finally, I wish to express my heartfelt thanks to all contributors, the members of ICMI, the members of the Honorary Committee, the members of the Program 
Committee and Organizing Committee, as well as the Secretary General of the conference, for all of their tireless work and cooperation. In particular, many thanks are due to Prof. Jiubin Tan for his contribution to the conference. Many thanks are also due to the Organizers and Cooperating Organizations, Harbin Institute of Technology, China Jiliang University, and Hefei University of Technology, for their warm reception as the hosts of the conference. Also, we appreciate very much and would like to thank the sponsors NSFC, CSM, and CIS, for their generous support of the conference.

We came to Hangzhou to promote precision engineering measurements and instrumentation as well as the friendship and cooperation between scholars and specialists in this field worldwide. I believe every participant can benefit from the conference.

It is a great pleasure for us to renew our existing friendly feelings and to make new friends during the conference. I am sure our friendship will live on and develop further as time goes by.

Prof. Li Zhu

Founding Chairman of ICMI Huazhong University of Science and Technology, Wuhan, CHINA

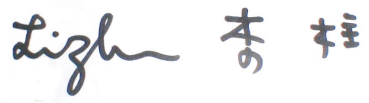




\section{Preface}

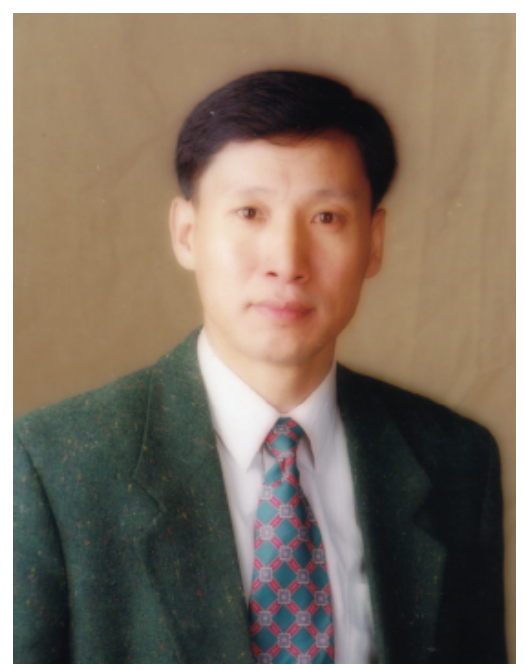

The International Symposium on Precision Engineering Measurements and Instrumentation (ISPEMI) is an international symposium held every other year in different cities of China with English as its working language. It originated from the International Symposium on Instrumentation Science and Technology (ISIST), which has been held for a total of five sessions. ISIST 1999, the first session, was held in Luoyang, Henan Province, ISIST 2002, the second session, in Jinan, Shandong Province, ISIST 2004, the third session, in Xi'an, Shanxi Province, ISIST 2006, the fourth session, in Harbin, Heilongjiang Province, and ISIST 2008, the fifth session, in Shenyang, Liaoning Province. From the second session of ISIST onward, Hefei University of Technology organized three sub-sessions on precision mechanical measurements (ISPMM) and held them in Beijing, Urumchi, Xinjiang Province, and Hefei, Anhui Province, respectively. This series of meetings has greatly promoted the academic exchange in this particular field. However, in order to efficiently use the resources available to run one important international symposium well, these two meetings were merged in 2010 into ISPEMI as suggested by the National Natural Science Foundation of China (NSFC), Chinese Society for Measurements (CSM), and China Instrument and Control Society (CIS). The merging of ISIST and ISPMM and the use of ISPEMI means the establishment of a more efficient platform for the academic exchange amongst well-accomplished scientists and postgraduates, both inside and outside China, to facilitate the in-depth discussion and cooperation in the field of precision engineering measurements and instrumentation.

ISPEMI 2010, the 6th ISPEMI, was held 8-11 August 2010, in Hangzhou, Zhejiang Province. More than 300 delegates attended the meeting. Plenary speakers from the U.S., U.K., Australia, Japan, Germany, Russian Federation, and China made excellent presentations on their work. A wide range of subjects was covered during session discussions. Two Chinese students received SPIE Best Student Paper Awards. From the 647 manuscripts received, we accepted only 257 papers for oral and poster presentation at the meeting. After the meeting, we worked together with authors to make sure all of the papers included in the proceedings of ISPEMI 2010 are good in both technical quality and English. 
While these proceedings from the ISPEMI 2010 is now ready for distribution to the authors, we would like to thank the National Natural Science Foundation of China (NSFC), International Committee on Measurements and Instrumentation (ICMI), Chinese Society for Measurement (CSM), China Instrument and Control Society (CIS), Harbin Institute of Technology (HIT), China Jiliang University (CJLU), and Hefei University of Technology (HFUT) for their funds and assistances provided. Our thanks go to the procedure and organizing committee members, especially honorary chairman, cochairmen, and plenary speakers, Prof. Li Zhu, Prof. Abou-Zeid, Prof. Fei Yetai, Prof. Tony Wilison, Dr. Harald Bosse, Prof. James Burge, Prof. Gao Wei, Prof. Gu Min, Prof. Alexander Poleshchuk, Prof. Zhang Xiang, Prof. Tim Watson and

Prof. Li Shengyi for their efforts to make the meeting fruitful and successful. And our special thanks go to SPIE for their efforts to enable us to do all these so well.

Prof. Jiubin Tan

Chair, ISPEMI 2010 Organizing Committee

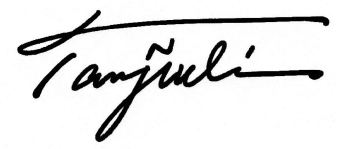

